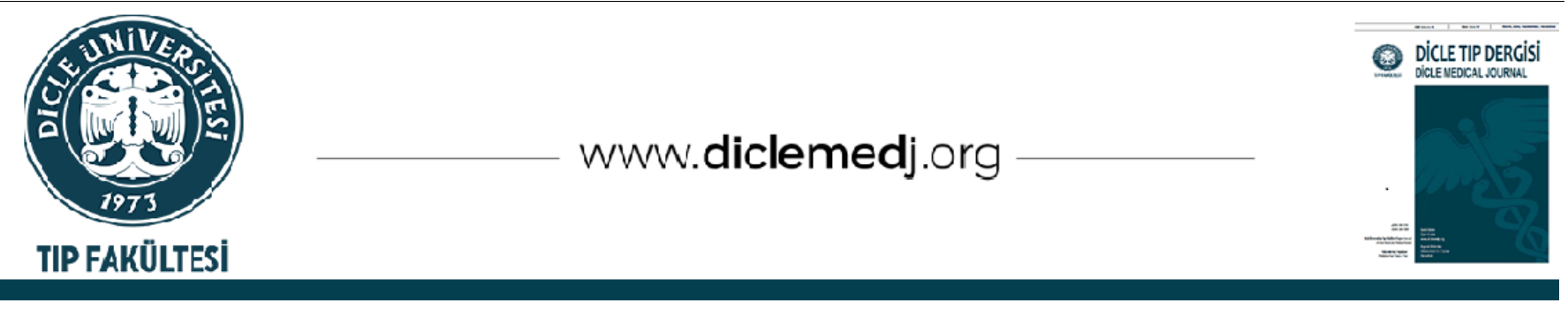

Özgün Araştırma / Original Article

\title{
Biyolojik İlaç Kullanan Romatoloji Hastalarında HBV ve HCV Seroprevalansı
}

\author{
Mehmet Ali Balcı iD 1 , Nazım Ekin ${ }^{\text {iD }} 2$ \\ 1 Romatoloji Uzmanı, İç Hastalıkları Romatoloji Kliniği, S.B.Ü Gazi Yaşargil Eğitim ve Araştırma Hastanesi, Diyarbakır, Türkiye \\ 2 Gastroenteroloji Uzmanı, İç Hastalıkları Gastroenteroloji Kliniği, S.B.Ü Gazi Yaşargil Ë̆itim ve Araştırma Hastanesi, Diyarbakır, Türkiye \\ Geliş: 20.10.2020; Revizyon: 30.11.2020; Kabul Tarihi: 07.12.2020
}

Öz

Amaç: Hepatit B virüsü (HBV) ve Hepatit C virüsü (HCV) enfeksiyonları küresel bir halk sağlığı sorunudur. Biyolojik ilaçlar, kronik HBV taşıyıcısı veya okült HBV enfeksiyonu olan hastalarda HBV enfeksiyonunun yeniden aktivasyonuna neden olabilir. Aynı şekilde Anti HCV pozitif olan hastalarda da HCV enfeksiyonunun reaktivasyonuna neden olabildiği bilinmektedir. Biz çalışmamızda biyolojik tedavi alan romatoloji hastalarında HBV ve HCV enfeksiyonlarının prevalansını araştırmayı amaçladık.

Yöntemler: 01/09/2017- 01/09/2020 tarihleri arasında Diyarbakır Sağlık Bilimleri Üniversitesi Gazi Yaşargil Eğitim ve Araştırma Hastanesi Romatoloji Polikliniği'ne başvuran ve biyolojik tedavi başlanan 582 hasta çalışmaya alındı. Retrospektif olarak demografik ve labaratuar özellikleri kayıt edildi. İstatistiksel analizler SPSS V22.0 (IBM SPSS Statistics, Armonk, NY) yazılımı ile yapıldı.

Bulgular: Çalışmamıza 342'si $(\% 58,8)$ kadın ve 240'ı (\%41,2) erkek olmak üzere toplam 582 hasta alındı. Çalışmaya alınan hastaların 290'unda (\%49,8) ankilozan spondilit (AS), 213'ünde (\%36,6) romatoid artrit (RA), 23'ünde $(\% 4,0)$ psöriatik artrit (PsA) tanısı mevcuttu. HBsAg \%1,4, Anti-HBs \%51,7, Anti-HBc IgG \%31,4 ve Anti-HCV \%0,3 oranlarında pozitif saptandı. Tanılara göre bakınca; AS'de HBsAg \%1,7, Anti-HBs \%53,1, Anti-HBc IgG \%38,9, Anti-HCV \%0,0, RA'da HBsAg \%1,4, Anti-HBs \%51,9, Anti-HBc IgG \%41,7, Anti-HCV \%0,5 oranlarında saptandı.

Sonuç: Ülkemizde hala HBV ve HCV enfeksiyonları orta endemik seviyede görülmektedir. Biyolojik tedaviler HBV ve HCV enfeksiyonlarının reaktivasyonuna neden olabileceğinden biyolojik tedavi öncesi bu enfeksiyonların taranması, profilaksisi ve tedavisi önemini hala korumaktadır.

Anahtar kelimeler: Hepatit B, Hepatit C, Biyolojik tedavi

\section{DOI: 10.5798/dicletip.850523}

Correspondence / Yazışma Adresi: Mehmet Ali Balcı, S.B.Ü Gazi Yaşargil Eğitim ve Araştırma Hastanesi, Diyarbakır, Türkiye e-mail: abalci13@gmail.com 


\title{
HBV and HCV Seroprevalence in Rheumatology Patients Using Biological Drugs
}

\begin{abstract}
Objective: Hepatitis B virus (HBV) and Hepatitis C virus (HCV) infections are a global public health problem. Biological drugs can cause reactivation of HBV infection in patients with chronic HBV carrier or occult HBV infection. Likewise, it is known that it can cause reactivation of HCV infection in patients who are positive for Anti HCV. In our study, we aimed to investigate the prevalence of $\mathrm{HBV}$ and $\mathrm{HCV}$ infections in rheumatology patients receiving biological therapy.

Method: 582 patients who applied to Diyarbakır Health Sciences University Gazi Yaşargil Training and Research Hospital Rheumatology Polyclinic between 01/09/2017 and 01/09/2020 and using biological treatment were included in the study. Demographic and laboratory characteristics were recorded retrospectively. Statistical analysis was performed with SPSS V22.0 (IBM SPSS Statistics, Armonk, NY) software.
\end{abstract}

Results: A total of 582 patients, 342 (58.8\%) female and 240 (41.2\%) male, were included in our study. Of the patients included in the study, 290 (49.8\%) were diagnosed with ankylosing spondylitis (AS), $213(36.6 \%)$ rheumatoid arthritis (RA), and 23 (4\%) psoriatic arthritis (PsA). HBsAg 1.4\%, Anti-HBs 51.7\%, Anti-HBc IgG 31.4\% and Anti-HCV 0.3\% were positive. Looking according to the diagnosis; In AS; HBsAg 1.7\%, Anti-HBs 53.1\%, Anti-HBc IgG 38.9\%, Anti-HCV 0.0\%, in RA; HBsAg was 1.4\%, Anti-HBs 51.9\%, Anti-HBc IgG 41.7\%, Anti-HCV 0.5\% were detected.

Conclusion: In our country, HBV and HCV infections are still seen at medium endemic levels. Since biological treatments may cause reactivation of HBV and HCV infections, screening, prophylaxis and treatment of these infections before biological treatment still maintains its importance.

Keywords: Hepatitis B, Hepatitis C, Biological therapy.

\section{GíRiş}

Hepatit B virüsü (HBV) enfeksiyonu, küresel bir halk sağlığı sorunudur. Dünya Sağlık Örgütü dünyada 257 milyon HBV taşıyıcısı olduğunu ve 2015 yılında HBV ile ilişkili karaciğer hastalığından yaklaşık 887.000 kişinin öldüğünü tahmin etmektedir. HBV yüzey antijeni (HBsAg) pozitifliğinin prevalansı coğrafik bölgeye göre değişebilmektedir. HBV prevalansı Amerika'da \%0,7, Avrupada \%1,6, Güneydoğu Asyada \%3,3, Afrikada \%6,1 saptanmıştır ${ }^{1}$. Dünya sağlık örgütü 71 milyon kişide kronik Hepatit C virüsü (HCV) enfeksiyonu olduğunu, 2016 yllında HCV ile ilişkili karaciğer hastalığından yaklaşık 399.000 kişinin öldüğünü tahmin etmektedir. HCV enfeksiyonu prevalansı Doğu Akdeniz'de \%2,3, Avrupa bölgesinde $\% 1,5$ olmak üzere diğer bölgelerde \%0,5 ila \%1,0 arasında değiștiği saptanmıştır². Ülkemizde yapılan seroprevelans çalışmasında ise HBV enfeksiyonu \%4,0, HCV enfeksiyonu ise $\% 1,0$ oranında saptanmıştır ${ }^{3}$.
Romatolojik hastalıkların tedavisinde, hastalık modifiye edici antiromatizmal ilaçlar (diseasemodifying antirheumatic drug; DMARD) tedavinin temelini oluşturmaktadır ${ }^{4}$. DMARD'lar kendi içinde sentetik DMARD ve biyolojik DMARD olmak üzere 2 alt gruba ayrılırlar. Biyolojik DMARD'lar; anti-TNF'ler (adalimumab, etanersept, infliksimab, golimumab, sertolizumab), B hücre blokörleri (rituximab), T hücre blokörleri (abatasept), IL6 blokörleri (tosilizumab), JAK-kinaz inhibitörleri (tofasitinib), IL17 blokeri (secukinumab) ilaçlarını kapsamaktadır ${ }^{5}$. Biyolojik DMARD kullanan ve kronik HBV taşıyıcılığı olan ya da okült HBV enfeksiyonu olan hastalarda HBV enfeksiyonunun reaktive olduğu bilinmektedir6. Bunula birlikte immünsüpresif tedavi sirasinda $\mathrm{HCV}$ reaktivasyonu, biyolojik tedavi gören romatizmal veya otoimmün hastalıklarda da görüldügü saptanmıştır ${ }^{7}$. Biyolojik ilaç tedavisi alan romatolojik hastalarda HBV ve HCV enfeksiyonlarının prevalansı tam olarak bilinmemektedir. Yaptığımız literatür 
taramasında da ülkemizde biyolojik tedavi kullanan hastalarda HBV ve HCV seroprevalans çalışmasına rastlanılmadı. Biz çalışmamızda biyolojik tedavi alan romatoloji hastalarında HBV ve HCV enfeksiyonlarının prevalansını araştırmayı amaçladık.

\section{YÖNTEMLER}

01/09/2017- 01/09/2020 tarihleri arasında Sağlık Bilimleri Üniversitesi Gazi Yaşargil Eğitim ve Araştırma Hastanesi Romatoloji Polikliniğ'ine başvuran ve biyolojik tedavi başlanan 582 hasta çalışmaya alındı. Hastaların yaş, cinsiyet, tanı, tedavi, HBsAg, HBV yüzey antikoru (anti-HBs), HCV antikoru (anti-HCV), HBV çekirdek antikoru immunoglobulin G (anti$\mathrm{HBc}$ IgG) verileri retrospektif olarak taranıp kayıt edildi. HBsAg, Anti-HBs, Anti-HCV, AntiHBc IgG testleri enzyme-linked immunosorbent assay (ELISA) yöntemi ile çalışıldı. HBsAg veya anti-HCV sonuçları pozitif olan hastalara ayrıca real-time PCR yöntemi ile HBV DNA veya HCV RNA çalışıldı. İstatistiksel analizler SPSS V22.0 (IBM SPSS Statistics, Armonk, NY) yazılımı ile yapıldı. Sürekli değişkenler ortalama sstandart sapma şeklinde belirtildi. $\mathrm{p}<0,05$ değeri istatistiksel olarak anlamlı kabul edildi. Sağlık Bilimleri Üniversitesi Gazi Yaşargil Eğitim ve Araștırma Hastanesinden 16.10.2020 tarihli 560 sayı no'lu etik kurul onayı alındı.

\section{BULGULAR}

Çalışmamıza 342'si $(\% 58,8)$ kadın ve 240'ı $(\% 41,2)$ erkek olmak üzere toplam 582 hasta alındı. Yaş ortalaması kadınlarda 46,2, erkeklerde 39,3 genel de ise 43,3 idi. Çalışmaya alınan hastaların 290'unda (\%49,8) ankilozan spondilit (AS), 213'ünde $(\% 36,6)$ romatoid artrit (RA), 23'ünde (\%4) psöriatik artrit (PsA) tanısı mevcuttu. Bu hastaların 122'si (\%21) golimumab, 111'i (\%19,1) adalimumab, 78'i $(\% 13,4)$ etanersept, 65'i $(\% 11,2)$ rituximab kullanmaktaydı. Hastaların ayrıntılı verileri Tablo I' de verilmiştir.
Tablo I: Hastaların genel klinik özellikleri ve kullanılan tedaviler

\begin{tabular}{|l|l|l|l|}
\hline $\begin{array}{l}\text { Toplam Hasta } \\
\text { sayısı }\end{array}$ & 582 & Yaş, genel & 43,3 \\
\hline Kadın sayısı & $342(\% 58,8)$ & Yaş, kadın & 46,2 \\
\hline Erkek sayısı & $240(\% 41,2)$ & Yaş, erkek & 39,3 \\
\hline Tanı & $290(\% 49,8)$ & Golimumab & $122(\% 21)$ \\
\hline AS & $213(\% 36,6)$ & Adalimumab & $111(\% 19,1)$ \\
\hline RA & $23(\% 4,0)$ & Etanersept & $78(\% 13,4)$ \\
\hline PsA & $18(\% 3,1)$ & Rituximab & $65(\% 11,2)$ \\
\hline Behçet & $9(\% 1,5)$ & Sertolizumab & $56(\% 9,6)$ \\
\hline SLE & $9(\% 1,5)$ & Tosilizumab & $49(\% 8,4)$ \\
\hline Takayasu & $6(\% 1,0)$ & İnfliksimab & $46(\% 7,9)$ \\
\hline Skleroderma & $5(\% 0,9)$ & Tofasitinib & $29(\% 5,0)$ \\
\hline Wegener & $4(\% 0,7)$ & Secukinumab & $20(\% 3,4)$ \\
\hline Sjögren & $2(\% 0,3)$ & Abatasept & $5(0,9)$ \\
\hline FMF & $1(\% 0,2)$ & Kanakinumab & $1(0,2)$ \\
\hline Dermatomiyozit & $1(\% 0,2)$ & & \\
\hline EBSH & $1(\%, 2)$ & & \\
\hline PMR & & & \\
\hline
\end{tabular}

AS: Ankilozan spondilit, RA: Romatoid artrit, PsA: Psöriatik artrit, SLE: Sistemik lupus eritematozus, FMF: Familial mediterranean fever (ailevi akdeniz ateși), EBSH: Erişkin bașlangıçlı Still hastalığı, PMR: polimiyalji romatika.

Hastaların hepsinden HBsAg, Anti-HBs, AntiHCV çalışılmış olup 483 (\%83) hastadan AntiHBc IgG çalışıldığı saptandı. Biyolojik tedavi kullanan romatolojik hastalarda genel seroprevelansa bakınca; HBsAg \%1,4 (8), AntiHBs \%51,7 (301), Anti-HBc IgG \%37,9 (183) ve Anti-HCV \%0,3 (2) oranlarında saptandı. HBsAg pozitif olan hastaların yaş ortalaması $(46,8 \pm 11.7)$ HBsAg negatif olanlara $(43,3 \pm 13.3)$ göre daha yüksek saptandı. Anti-HCV pozitif olan hastaların yaş ortalamaları $(51 \pm 24)$ AntiHCV negatif olanlara göre $(43,3 \pm 13.9)$ daha yüksek saptandı. HBsAg pozitifliği erkeklerde kadınlara oranla daha fazla (5/3), Anti-HCV pozitifliği kadınlarda erkekler oranla daha fazla $(2 / 0)$ tespit edildi.

Tanılara göre bakınca; AS'de HBsAg \%1,7, AntiHBs \%53,1, Anti-HBc IgG \%38,9, Anti-HCV 
$\% 0,0$, RA'da HBsAg \%1,4, Anti-HBs \%51,9, AntiHBc IgG \%41,7, Anti-HCV \%0,5 oranlarında saptandı. Ayrıntılı veriler Tablo II'de verilmiştir. HBsAg pozitif olan 8 hastanın HBV DNA'sl, AntiHCV pozitif olan 2 hastanın HCV RNA'sı negatifti. Hastaların AST, ALT değerleri normaldi. İki hastada hem HBsAg hem de AntiHBs pozitif saptand. HBsAg veya Anti-HCV pozitif olan hiçbir hasta anti-TNF tedavi öncesi antiviral tedavi almiyordu.

Tablo II: Tanı dağılımına göre seroprevalans oranları

\begin{tabular}{|c|c|c|c|c|}
\hline & HBsAg & Anti-HBs & \begin{tabular}{|l} 
Anti-HBc \\
IgG
\end{tabular} & $\begin{array}{l}\text { Anti- } \\
\text { HCV }\end{array}$ \\
\hline AS & $5(\% 1,7)$ & $154(\% 53,1)$ & $93(\% 38,9)$ & $0(\% 0,0)$ \\
\hline$\overline{\text { RA }}$ & $3(\% 1,4)$ & $110(\% 51,9)$ & $75(\% 41,7)$ & $1(\% 0,5)$ \\
\hline PsA & $0(\% 0,0)$ & $9(\% 39,1)$ & $5(\% 27,8)$ & $0(\% 0,0)$ \\
\hline Behçet & $0(\% 0,0)$ & $8(\% 44,4)$ & $3(\% 21,4)$ & $0(\% 0,0)$ \\
\hline SLE & $0(\% 0,0)$ & $5(\% 55,6)$ & $2(\% 25)$ & $0(\% 0,0)$ \\
\hline Takayasu & $0(\% 0,0)$ & $3(\% 33,3)$ & $2(\% 33,3)$ & \begin{tabular}{|l|}
1 \\
$(\% 11,1)$
\end{tabular} \\
\hline Skleroderma & $0(\% 0,0)$ & $1(\% 16,7)$ & $0(\% 0,0)$ & $0(\% 0,0)$ \\
\hline Wegener & $0(\% 0,0)$ & $3(\% 60)$ & $1(\% 20)$ & $0(\% 0,0)$ \\
\hline \begin{tabular}{|l|} 
Sjögren \\
\end{tabular} & $0(\% 0,0)$ & $3(\% 75)$ & $1(\% 33,3)$ & $0(\% 0,0)$ \\
\hline FMF & $0(\% 0,0)$ & $1(\% 50)$ & $0(\% 0,0)$ & $0(\% 0,0)$ \\
\hline Dermatomiyozit & $0(\% 0,0)$ & $1(\% 100)$ & $1(\% 100)$ & $0(\% 0,0)$ \\
\hline EBSH & $0(\% 0,0)$ & $1(\% 100)$ & $0(\% 0,0)$ & $0(\% 0,0)$ \\
\hline PMR & $0(\% 0,0)$ & $1(\% 100)$ & $0(\% 0,0)$ & $0(\% 0,0)$ \\
\hline Genel & $8(\% 1,4)$ & $301(\% 51,7)$ & $183(\% 37,9)$ & $2(\% 0,3)$ \\
\hline
\end{tabular}

AS: Ankilozan spondilit, RA: Romatoid artrit, PsA: Psöriatik artrit, SLE: Sistemik lupus eritematozus, FMF: Familial mediterranean fever (ailevi akdeniz ateşi), EBSH: Erişkin başlangıçlı Still hastalığı, PMR: polimiyalji romatika.

Biyoloijk tedavilere göre $\mathrm{HbsAg}$ ve anti-HCV seroprevalansı sirasıyla; etanersept alan hastalarda $\% 3,8$ ve $\% 0,0$, golimumab alan hastalarda $\% 0,8$ ve $\% 0,0$, adalimumab alan hastalarda $\% 0,9$ ve $\% 0,9$ oranında saptandı. Ayrıntılı veriler Tablo III'te verilmiştir.
Tablo III: Tedavide kullanılan biyolojik ajanlarda saptanan seroprevalans oranları

\begin{tabular}{|l|l|l|l|l|}
\hline & HBsAg & Anti-HBs & Anti-HBc IgG & $\begin{array}{l}\text { Anti- } \\
\text { HCV }\end{array}$ \\
\hline Golimumab & $1(\% 0,8)$ & $61(\% 50)$ & $35(\% 35,0)$ & $0(\% 0,0)$ \\
\hline Adalimumab & $1(\% 0,9)$ & $58(\% 52,3)$ & $30(\% 35,3)$ & $1(\% 0,9)$ \\
\hline Etanersept & $3(\% 3,8)$ & $37(\% 47,4)$ & $31(\% 48,4)$ & $0(\% 0,0)$ \\
\hline Rituximab & $0(\% 0,0)$ & $27(\% 42,2)$ & $18(\% 30,5)$ & $0(\% 0,0)$ \\
\hline Sertolizumab & $1(\% 1,8)$ & $32(\% 57,1)$ & $22(\% 43,1)$ & $0(\% 0,0)$ \\
\hline Tosilizumab & $1(\% 2,0)$ & $30(\% 61,2)$ & $15(\% 40,5)$ & $1(\% 2,0)$ \\
\hline İnfliksimab & $1(\% 2,2)$ & $24(\% 52,2)$ & $11(\% 28,9)$ & $0(\% 0,0)$ \\
\hline Tofasitinib & $0(\% 0,0)$ & $17(\% 58,6)$ & $17(\% 63,0)$ & $0(\% 0,0)$ \\
\hline Secukinumab & $0(\% 0,0)$ & $9(\% 45,0)$ & $4(\% 23,5)$ & $0(\% 0,0)$ \\
\hline Abatasept & $0(\% 0,0)$ & $4(\% 80,0)$ & $0(\% 0,0)$ & $0(\% 0,0)$ \\
\hline Kanakinumab & $0(\% 0,0)$ & $1(\% 100)$ & $0(\% 0,0)$ & $0(\% 0,0)$ \\
\hline Genel & $8(\% 1,4)$ & $301(51,7)$ & $183(\% 37,9)$ & $2(\% 0,3)$ \\
\hline
\end{tabular}

Yaşa göre seroprevalansa baktığımızda HBsAg pozitifliğinin $4,5,6$ ve 7 . dekata yayıldığını görmekteyiz. Yaş arttıkça Anti-HBs pozitifliğinin azaldığını görmekteyiz. Anti-HCV pozitifliği ise sadece 4 . ve 7 . dekatta 1'er vaka olarak görmekteyiz. Ayrıntılı veriler Tablo IV'te verilmiştir.

Tablo IV: Yaş gruplarına göre seroprevalans oranları

\begin{tabular}{|l|l|l|l|l|}
\hline $\begin{array}{l}\text { Yas } \\
\text { Grubu }\end{array}$ & HBsAg & Anti-HBs & Anti-HBc IgG & Anti-HCV \\
\hline $\mathbf{1 8 - 2 9}$ & $0(\% 0,0)$ & $74(\% 69,8)$ & $26(\% 33,3)$ & $0(\% 0,0)$ \\
\hline $\mathbf{3 0 - 3 9}$ & $3(\% 2,0)$ & $66(\% 44,6)$ & $47(\% 38,8)$ & $1(\% 0,7)$ \\
\hline $\mathbf{4 0 - 4 9}$ & $1(\% 0,6)$ & $65(\% 42,2)$ & $50(\% 39,1)$ & $0(\% 0,0)$ \\
\hline $\mathbf{5 0 - 5 9}$ & $3(\% 3,5)$ & $39(\% 45,9)$ & $33(\% 44,0)$ & $0(\% 0,0)$ \\
\hline $\mathbf{6 0 - 6 9}$ & $1(\% 1,6)$ & $42(\% 68,9)$ & $19(\% 33,3)$ & $1(\% 1,6)$ \\
\hline $\mathbf{7 0 - 7 9}$ & $0(\% 0,0)$ & $14(\% 53,8)$ & $8(\% 34,8)$ & $0(\% 0,0)$ \\
\hline $\mathbf{8 0 - 8 9}$ & $0(\% 0,0)$ & $0(\% 0,0)$ & $0(\% 0.0)$ & $0(\% 0,0)$ \\
\hline $\mathbf{9 0 - 9 9}$ & $0(\% 0,0)$ & $1(\% 100)$ & $0(\% 0.0)$ & $0(\% 0,0)$ \\
\hline Genel & $8(\% 1,4)$ & $301(51, .7)$ & $183(\% 37,9)$ & $2(\% 0,3)$ \\
\hline
\end{tabular}




\section{TARTIŞMA}

Çalışmamızda biyolojik tedavi kullanan romatolojik hastalı̆̆ olan hastalarda HBsAg $\% 1,4$, Anti-HBc IgG \%37,9, Anti-HBs \%51,7 ve Anti-HCV \%0,3 oranlarında saptandı. Ülkemizde toplum bazlı yapılan seroprevelans çalışmasında HBsAg \%4,0, anti-HBc total $\% 30,6$, anti-HBs \%37,9 ve anti-HCV \%1,0 oranında pozitif saptanmıștır ${ }^{3}$. Tayvan'da yapılan çalışmada TNF kullanan 472 hastanın katıldığı çalışmada HBsAg \%7,4, izole HBcAb \%59,8 pozitif saptanmış 8 . Çalışmamızda HBsAg ve Anti-HCV pozitiflik oranları ülkemize göre daha düşük, anti-HBc IgG ve anti-HBs oranı ise daha yüksek saptanmıştır. Bunun nedenlerinden biri ülkemizde yapılan çalışmalarda da gösterildiği gibi ${ }^{9}$ yaygın aşılamanın devam etmesi ve iki çalışma arasında 6 yıl gibi bir süre olması olabilir. Tayvan'da yapılan çalışmaya göre hem HBsAg hem de Anti-HBc IgG daha düşük oranlarda tespit edilmiştir. Tayvan'ın yüksek endemisiteye sahip olması, Türkiye'nin ise orta endemisiteye sahip olması Tayvan'daki HBsAg ve anti-HBc IgG oranlarının yüksekliğini açıklayabilmektedir.

Anti-HBc IgG testi çalışılan 483 hastadan \%17,4'ünde izole Anti-HBc IgG pozitifliği saptandı. Ülkemizden yapılan toplum bazlı bir çalışmada ise bu oran \%4,6 olarak saptanmıştır ${ }^{3}$. Literatürde immünsüpresif ilaç veya kemoterapi alan hastalarda, izole Anti-HBc IgG prevalansı $\% 11^{10}$ ile $\% 18,1^{11}$ arasinda değişmektedir. Bulduğumuz veriler ülkemizdeki çalışmaya oranla daha yüksek çlksa da literatür ile uyumludur.

AS'de HBsAg prevalansı \%1,7, Anti-HBc IgG prevalansı \%38,9, Anti-HCV prevalansı \%0,0 saptandı. Tayvan'dan yapılan çalışmada 86 AS hastasının \%9,3'ünde $\mathrm{HbAg}$ pozitif, \%45,3'ünde izole $\mathrm{HBcAb}$ pozitif saptanmış ${ }^{8}$ Çin'in güneyinden yaplan çalışmada 334 As hastasının \%23,9'unda HBsAg pozitif saptanmış ${ }^{12}$. Ülkemizde yapılan çalışmada AS hastalarında HBsAg prevalansı \%3, Anti-HCV prevalansı $\% 1,1$ oranında saptanmış ${ }^{13}$. Çalışmamızda AS hastalarında HBsAg prevalansı literatüre göre çok daha düşük saptanmıştır.

RA'da HBsAg prevalansı \%1,4, Anti-HBc IgG prevalansı \%41,7, Anti-HCV prevalansı \%0,5 oranında saptandı. Tayvan'dan yapılan çalışmada 336 RA hastasının \%7,4'ünde HBsAg pozitif, \%64,6'ünde izole HBcAb pozitif saptanmış ${ }^{8}$. Japonya'dan yapılan çalışmada 1351 RA'lı hastalanın \%3,7'sinde HBsAg pozitif saptanmış ${ }^{14}$ İtalya'da RA'lı hastaların araştırıldığı çalışmada \%0,2 oranında HBsAg pozitif, yine \%0,2 oranında izole anti-HBc IgG pozitifliği ve \%1,7 oranında Anti-HCV pozitifliği saptanmış ${ }^{15}$. Yine ülkemizde yapılan çalışmada RA'lı hastalarında HBsAg prevalansı \%2,3, AntiHCV prevalansı \%1,1 oranında saptanmış ${ }^{13}$. Bizim çalışmamızda RA'lı hastalarda HBsAg prevalansı Tayvan, Japonya ve ülkemize göre daha düşük, İtalya'ya göre daha yüksek saptanmiştır.

PsA hastalarında HBsAg prevalansı \%0,0, AntiHBc IgG prevalansı \%27,8, Anti-HCV prevalansı $\% 0,0$ olarak saptandı. Yine Tayvan'dan yapılan çalışmada 50 PsA hastasının katıldığı çalışmada $\% 4,0$ oranında HBsAg pozitifliği, \%52,0 oranında izole $\mathrm{HBcAb}$ pozitifliği saptanmış. İtalya'dan yapılan çalışmada 111 PsA hastasının \%12,6'sında HBsAg pozitifliği, \%11,7'sinde izole Anti-HBc IgG pozitifliği, \%5,4'ünde AntiHCV pozitifliği saptanmış ${ }^{16}$. Biz literatüre göre PsA hastalarımızda HBsAg pozitifliğini daha düşük saptadık. Bunun nedeni literatürdeki vaka serilerine oranla PsA'lı hasta sayımızın az olması olabilir.

Sistemik lupus eritematozus (SLE) hastalarında HBsAg prevalansı \%0,0, Anti-HBc IgG prevalansı \%25,0, Anti-HCV prevalansı \%0,0 olarak saptandı. Literatüre bakınca Çin'den yapılan bir çalışmada SLE'li hastalarda HBsAg prevalansı $\% 2,3$ oranında bildirildiği görüldü17. Tayvan'dan yapılan çalışmada 158 SLE 
hastasının \%15,2'sinde HBsAg pozitifliği, $\% 16,5$ 'sında Anti-HCV pozitifliği saptanmış ${ }^{18}$. Biz literatüre göre SLE hastalarımızda da HBsAg pozitifliğini daha düşük saptadık. Bunun nedeni de yine literatürdeki vaka serilerine oranla SLE'li hasta sayımızın az olması olabilir.

Çalışmamızda HBsAg pozitifliği en yüksek 6 . dekatta \%3,5, en yüksek Anti-HCV pozitifliği ise 7. dekatta $(\% 1,6)$ olarak saptanmıștır. Ülkemizden bildirilen yayında ise HBsAg pozitifliği en yüksek 4 . dekatta $\% 24,8$ ve 5 . dekatta $\% 25,3$, Anti-HCV pozitifliği ise 6.dekatta \%19 olarak saptanmıștır³.

Sonuç olarak; ülkemizde hala HBV ve HCV enfeksiyonları orta endemik seviyede görülmektedir. Biyolojik tedaviler HBV ve HCV enfeksiyonlarının reaktivasyonuna neden olabileceğinden biyolojik tedavi öncesi bu enfeksiyonların taranması, profilaksisi ve tedavisi önemini hala korumaktadır.

Etik Kurul Onayı: Sağlık Bilimleri Üniversitesi Gazi Yaşargil Eğitim ve Araştırma Hastanesinden 16.10 .2020 tarihli 560 sayı no'lu etik kurul onayı alındı.

Çıkar Çatışması Beyanı: Yazarlar çıkar çatışması olmadığını bildirmişlerdir.

Finansal Destek: Bu çalışma herhangi bir fon tarafından desteklenmemiştir.

Declaration of Conflicting Interests: The authors declare that they have no conflict of interest.

Financial Disclosure: No financial support was received.

\section{KAYNAKLAR}

1. Hepatitis B [https://www.who.int/newsroom/fact-sheets/detail/hepatitis-b]

2. Hepatitis C [https://www.who.int/newsroom/fact-sheets/detail/hepatitis-c]

3. Tozun N, Ozdogan O, Cakaloglu Y, et al. Seroprevalence of hepatitis B and C virus infections and risk factors in Turkey: a fieldwork TURHEP study. Clin Microbiol Infect. 2015; 21: 1020-6.

4. Smolen JS, Landewe R, Bijlsma J, et al. EULAR recommendations for the management of rheumatoid arthritis with synthetic and biological disease-modifying antirheumatic drugs: 2016 update. Ann Rheum Dis. 2017; 76: 960-77.

5. Sharma SK. Use of Biologics and Biosimilars in Rheumatology. J Assoc Physicians India. 2017; 65: 914.

6. Su J, Long L, Zou K. Antiviral prophylaxis for preventing reactivation of hepatitis $B$ virus in rheumatic patients: a systematic review and metaanalysis. Clin Rheumatol. 2018; 37: 3201-14.

7. Mok CC. Hepatitis B and C infection in patients undergoing biologic and targeted therapies for rheumatic diseases. Best Pract Res Clin Rheumatol. 2018; 32: 767-80.

8. Chiu YM, Lai MS, Chan KA. Commensurate incidence and outcomes of liver enzyme elevation between anti-tumor necrosis factor users with or without prior hepatitis B virus infections. PLoS One. 2018; 13: e0196210.

9. Özekinci T, Atmaca S, Akpolat N, Gül K. Güneydoğu Anadolu Bölgesi'nde Rutin Hepatit B Așı Programının Etkisi. Dicle Tıp Dergisi / Dicle Medical Journal. 2017; 44: 283-5.

10. Schwaneck EC, Krone M, Kreissl-Kemmer S, et al. Management of anti-HBc-positive patients with rheumatic diseases treated with disease-modifying antirheumatic drugs-a single-center analysis of 2054 patients. Clin Rheumatol. 2018; 37: 2963-70.

11. Su YC, Lin PC, Yu HC, Wu CC. Hepatitis B virus reactivation in patients with resolved hepatitis $B$ virus infection receiving chemotherapy or immunosuppressive therapy. Eur J Gastroenterol Hepatol. 2018; 30: 925-9.

12. Zheng B, Li T, Lin Q, et al. Prevalence of hepatitis $B$ surface antigen in patients with ankylosing spondylitis and its association with HLA-B27: a retrospective study from south China. Rheumatol Int. 2012; 32: 2011-6.

13. Yilmaz N, Karadag O, Kimyon G et al. Prevalence of hepatitis B and C infections in rheumatoid 
arthritis and ankylosing spondylitis: A multicenter countrywide study. Eur J Rheumatol. 2014; 1: 51-4.

14. Matsuzaki T, Eguchi K, Nagao N et al. Hepatitis B virus reactivation in patients with rheumatoid arthritis: A single-center study. Mod Rheumatol. 2018; 28: 808-13.

15. Ballanti E, Conigliaro P, Chimenti MS et al. Use of anti-tumor necrosis factor alpha therapy in patients with concurrent rheumatoid arthritis and hepatitis B or hepatitis C: a retrospective analysis of 32 patients. Drug Dev Res. 2014;75 Suppl 1: S42-5.
16. Morisco F, Guarino M, La Bella S, et al. Lack of evidence of viral reactivation in HBsAg-negative HBcAb-positive and HCV patients undergoing immunosuppressive therapy for psoriasis. BMC Gastroenterol. 2014; 14: 214.

17. Zhao J, Qiu M, Li M, Lu C, Gu J. Low prevalence of hepatitis B virus infection in patients with systemic lupus erythematosus in southern China. Rheumatol Int. 2010; 30: 1565-70.

18. Chen $\mathrm{MH}$, Chen $\mathrm{MH}$, Tsai CY, et al. Incidence and antiviral response of hepatitis $\mathrm{C}$ virus reactivation in lupus patients undergoing immunosuppressive therapy. Lupus. 2015; 24: 1029-36. 